\title{
CrystEngComm
}

Check for updates

Cite this: CrystEngComm, 2018, 20, 3817

Received 23rd May 2018,

Accepted 12th June 2018

DOI: $10.1039 / \mathrm{c} 8 \mathrm{ce} 00859 \mathrm{k}$

rsc.li/crystengcomm

Liquid assisted grinding using imidazolium-based ionic liquids (IL-AG) was found to be effective in isolation of cocrystals and cocrystal polymorphs. Isolation of specific polymorphs of caffeinecitric acid (CAF-CA) and caffeine-glutaric acid (CAF-GLU) cocrystals highlights the tunability of ILs in polymorphic control.

The study of cocrystals has become an attractive area of crystallization science in general and crystal engineering in particular because of their fundamental and practical importance. ${ }^{1}$ From a fundamental perspective, crystallization, ${ }^{2}$ mainly used as a purification technique, is prone to produce single component crystals and therefore design of cocrystals, which are essentially multi-component, enhances the understanding of the relative importance of various interactions that are involved in the crystallization process. ${ }^{3}$ This aspect of cocrystal synthesis has been explored recently by adopting the concept of structural landscape. ${ }^{4}$ Sometimes, cocrystals may also serve as an alternative to molecular synthesis. ${ }^{5,6}$ Both these aspects have garnered significant attention from solid-state chemists in recent times and cocrystals with increasing structural complexity and diverse applications have been synthesized. ${ }^{7-9}$

This growing interest in cocrystal synthesis calls for adoption of variegated experimental techniques. Although cocrystals are traditionally synthesized by slow solvent evaporation, this suffers from environmental hazards due to excessive solvent evaporation and from the lack of quantitative yield. As an alternative to this, mechanochemical approaches were sought. ${ }^{10,11}$ While these approaches can be broadly divided into two sub-categories, such as neat grinding (NG) and liquid assisted grinding (LAG), the latter has attracted a lot of attention recently due to its ability to produce

\footnotetext{
${ }^{a}$ Novartis-MIT Center for Continuous Manufacturing, and Department of Chemical Engineering, Massachusetts Institute of Technology, 77 Massachusetts Avenue, Cambridge, Massachusetts 02139, USA. E-mail: myerson@mit.edu

${ }^{b} 525$ Solutions, Inc., P.O. Box 2206, Tuscaloosa, AL 35403, USA

$\dagger$ Electronic supplementary information (ESI) available. See DOI: 10.1039/ c8ce00859k
}

cocrystals that are otherwise difficult to synthesize. ${ }^{12}$ Despite its great success in obtaining new cocrystals, LAG has sometimes suffered undesired outcomes. ${ }^{13}$ In this regard, Jones and coworkers have recently adopted a polymer based grinding approach (POLAG) which provides an alternative to traditional solvent based grinding. ${ }^{14,15}$ This approach was inspired by polymer-induced nucleation studies of organic molecules in the past ${ }^{16}$ and has shown that by changing the polarity of the ethylene glycol (EG) derivatives, the cocrystallization outcome can be controlled. More intriguingly, it was noted that the chemical nature of the microenvironment of the EG derivatives is likely to influence the nucleation and growth stages of cocrystal formation.

Ionic liquids (ILs) exhibit short and long range interactions between the positively and negatively charged ionic components and therefore are very different from traditional solvents. ${ }^{17}$ Although these types of interactions are complex in nature, recently we have shown that the effect of certain ILs can be studied with respect to crystallization and polymorphism. ${ }^{18,19}$ In analogy with the POLAG approach as mentioned above, we hypothesized that changing the structural variables of suitable ILs by changing either of the components may give us access to desirable cocrystals. While the chain length of the EG derivatives could be only variable in POLAG, the structural variables of ILs can be controlled either by individual tuning of the components or in a dual manner, increasing the number of variables in the grinding process. To check the viability of our approach we have chosen two cocrystal systems: (i) caffeine-citric acid (CAF-CA), where cocrystals (Form I) can only be obtained by the LAG technique, illustrating the importance of the grinding liquid, and (ii) caffeine-glutaric acid (CAF-GLU) where the polymorphic outcome can be controlled by tuning the structural variables of the grinding solvents.

Inorganic ionic salts have been employed earlier to demonstrate improved synthesis of metal organic frameworks. In order to prepare $\left[\mathrm{Zn}_{2}(\mathrm{ta})_{2}(\mathrm{dabco})\right]$, required amounts of zinc oxide was mixed with terephthalic acid (ta) and 1,4- 
diazabicyclo[2.2.2] octane (dabco) and ground in presence of some inorganic salts (such as potassium nitrate) with dimethyl formamide as a grinding solvent. This approach was termed as ion and liquid assisted grinding (ILAG). ${ }^{20}$ However, this is the first time, to the best of our knowledge, where liquid salts (ILs) are employed in liquid-assisted grinding to form cocrystals of organic compounds. In order to differentiate with the previous approach (ILAG), we term it as ionic liquid-assisted grinding (IL-AG).

Our objectives were to determine whether ILs have any role as grinding solvent when used in catalytic amount in mechanochemical grinding, and if they have a role, to determine how they affect the crystallization outcome. The first cocrystal system we studied was caffeine-citric acid (CAFCA). This cocrystal system has two polymorphic forms (CSD Refcodes: KIGKER, KIGKER01). While screened through techniques based on organic solvents, cocrystals of Form I were obtained only by $\mathrm{LAG}^{21}$ while the Form II was obtained from a chloroform/methanol solution. ${ }^{22}$ However, no cocrystals were obtained by NG. ${ }^{21}$ Later, POLAG was shown to be effective in isolating the Form I cocrystal. ${ }^{14}$ As Form I of this cocrystal system can only be obtained either by LAG or by POLAG, it demonstrates the importance of the grinding liquid in obtaining the Form I (Scheme 1).

We chose imidazolium-based ILs with relatively inert anions as grinding liquids because of their utility in crystallization of small molecules in previous studies. ${ }^{19}$ While previous studies employed different solvents or polymers of varying chain lengths, the focus of our strategy involved tuning the ILs either by modifying the substitution on the imidazolium cation or by changing the anions. The ILs studied, included 1-ethyl-3-methyl imidazolium bis(trifluoromethylsulfonylimide) $\quad\left(\left[\mathrm{C}_{2} \mathrm{mim}\right]\left[\mathrm{NTf}_{2}\right]\right)$, 1-butyl-3methyl imidazolium bis(trifluoromethylsulfonylimide) $\left(\left[\mathrm{C}_{4} \mathrm{mim}\right]\left[\mathrm{NTf}_{2}\right]\right)$ 1-methyl-3-octyl imidazolium bis(trifluoromethylsulfonylimide) ([ $\left.\left.\mathrm{C}_{8} \mathrm{mim}\right]\left[\mathrm{NTf}_{2}\right]\right)$, 1-dodecyl-3methyl imidazolium bis(trifluoromethylsulfonylimide) $\left(\left[\mathrm{C}_{12} \mathrm{mim}\right]\left[\mathrm{NTf}_{2}\right]\right)$, 1-hydroxyethyl-3-methyl-imidazolium bis(trifluoromethylsulfonylimide) $\quad\left(\left[\mathrm{OHC}_{2} \mathrm{mim}\right]\left[\mathrm{NTf}_{2}\right]\right)$, 1-ethyl3-methyl-imidazolium tetrafluoroborate $\left(\left[\mathrm{C}_{2} \mathrm{mim}\right]\left[\mathrm{BF}_{4}\right]\right)$, 1-hydroxyethyl-3-methyl-imidazolium tetrafluoroborate $\left(\left[\mathrm{OHC}_{2} \mathrm{mim}\right]\left[\mathrm{BF}_{4}\right]\right)$ (for chemical diagrams of the ILs, please see ESI $\dagger$ ). These ILs are diverse with respect to important key parameters. $\left[\mathrm{C}_{2} \mathrm{mim}\right]\left[\mathrm{NTf}_{2}\right]$ and $\left[\mathrm{C}_{2} \mathrm{mim}\right]\left[\mathrm{BF}_{4}\right]$ differ in hydrophobicity $\left(\left[\mathrm{C}_{2} \mathrm{mim}\right]\left[\mathrm{NTf}_{2}\right]\right.$ being hydrophobic and $\left[\mathrm{C}_{2} \mathrm{mim}\right]$ -

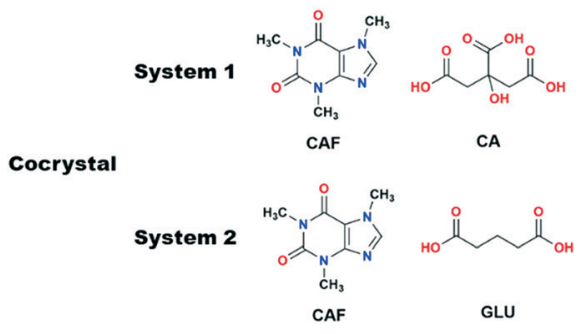

Scheme 1 The cocrystal systems used in this study.
$\left[\mathrm{BF}_{4}\right]$ being hydrophilic). ${ }^{23-25}$ Hydroxy ILs ([OHC $\left.\mathrm{OHim}_{2}\right]\left[\mathrm{NTf}_{2}\right]$ and $\left(\left[\mathrm{OHC}_{2} \mathrm{mim}\right]\left[\mathrm{BF}_{4}\right]\right)$ can sustain enhanced hydrogen bonding ability compared to $\left[\mathrm{C}_{2} \mathrm{mim}\right]\left[\mathrm{NTf}_{2}\right]$ ) or $\left[\mathrm{C}_{2} \mathrm{mim}\right]\left[\mathrm{BF}_{4}\right]($ e.g. $\left[\mathrm{OHC}_{2} \mathrm{mim}\right]\left[\mathrm{NTf}_{2}\right]$ possesses unusual hyper polarity $\left.{ }^{26}\right)$.

The ILs, were stored in a protected environment (in a glovebox and under vacuum) and were shown to have minimal water content (for details see ESI $\dagger$ ) prior to use. CAF-CA cocrystal formation was monitored mainly through the low $2 \theta$ peaks (See ESI $\dagger$ for the full range diffractograms). Form I of the cocrystals is identified by peaks around $2 \theta=10.5^{\circ}$, $12.5^{\circ}$ and $13^{\circ}$ (blue bands, Fig. 1). Peaks at ca. $2 \theta=12^{\circ}$ indicated the presence of unreacted CAF (grey band) and at $c a$. $14^{\circ}$ unreacted CA (red band, Fig. 1). During the grinding experiment, two coformers were taken in 1:1 molar ratio and placed in a mortar. Approximately, $40 \mu \mathrm{L}$ of IL was added thereafter and the mixture was ground with a pestle for 15 minutes approximately.

We first tried to grind the neat powders (NG) of CAF and CA and confirmed previous studies that NG (Fig. 1g) does not produce cocrystals. ${ }^{21}$ Next, we carried out the grinding with $\left[\mathrm{C}_{2} \mathrm{mim}\right]\left[\mathrm{NTf}_{2}\right]$, and the powder obtained after grinding shows dominant presence of Form I. Along with, a significant amount of unreacted CAF and a slight amount of CA was also present in the grinding mixture. Formation of Form I cocrystals was also observed when the grinding liquid was changed to $\left[\mathrm{C}_{2} \mathrm{mim}\right]\left[\mathrm{BF}_{4}\right]$ or $\left[\mathrm{OHC}_{2} \mathrm{mim}\right]\left[\mathrm{NTf}_{2}\right]$ keeping similar grinding conditions. However, the decreased relative intensity of the CAF peak suggests towards higher rate of cocrystal formation in these ILs. Although employing $\left[\mathrm{OHC}_{2} \mathrm{mim}\right]\left[\mathrm{BF}_{4}\right]$ as a grinding liquid also generated Form I as one of the products, the lowest $2 \theta$ peak is split, suggesting the presence of other products. Taking all the results into account, it can be said that the formation of Form I of CAF-CA cocrystals were not affected only by the hydrophobicity/hydrophilicity of the ILs, instead the hydrogen bonding ability of the IL cations may also have a key role.

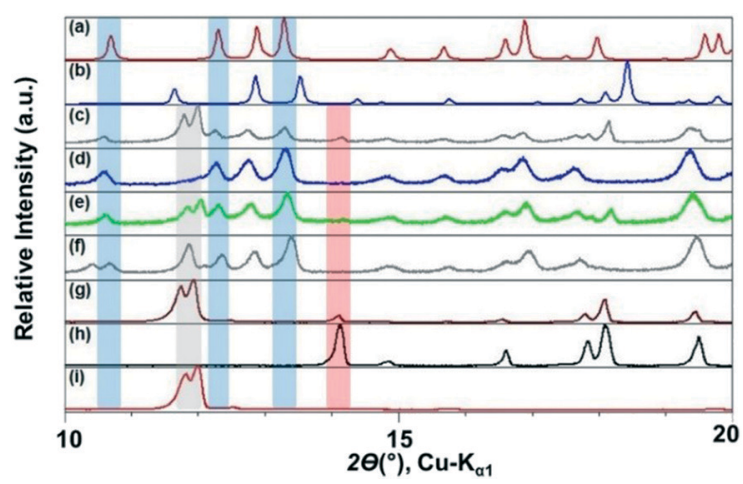

Fig. 1 Simulated pattern of the cocrystal, CAF-CA, Form I (Pī) (a) and CAF-CA, Form II $\left(P 2_{1} / C\right)(b)$; the ground powder as obtained from $\left[\mathrm{C}_{2} \mathrm{mim}\right]\left[\mathrm{NTf}_{2}\right](\mathrm{c}),\left[\mathrm{C}_{2} \mathrm{mim}\right]\left[\mathrm{BF}_{4}\right](\mathrm{d}),\left[\mathrm{OHC}_{2} \mathrm{mim}\right]\left[\mathrm{NTf}_{2}\right](\mathrm{e}),\left[\mathrm{OHC}_{2} \mathrm{mim}\right]\left[\mathrm{BF}_{4}\right]$ (f); experimental pattern of the powder mixture of $\mathrm{CAF}$ and $\mathrm{CA}$ obtained from neat grinding (g), and CA (h) and CAF (i) used in the grinding experiments. 
Having successfully demonstrated the utility of IL-AG technique for the CAF-CA system, we proceeded to investigate the cocrystal system of caffeine and glutaric acid (CAF-GLU). In this system, there are two forms: Form I is meta-stable and converts to Form II under certain conditions (CSD refcodes: EXUQUJ and EXUQUJ01). ${ }^{27,28}$ Both the forms can be prepared through solution crystallization, as well as mechanochemical techniques. ${ }^{29}$ While NG of the two coformers results in the formation of Form I, LAG gives access to both the forms: Form I is obtained when ground with non-polar liquids (e.g., hexane or heptane) whereas Form II is prepared by grinding with polar solvents (e.g., acetonitrile or dichloromethane). The POLAG approach employed polymers of varying EG chains and it was observed that by increasing the non polar EG units with respect to terminal polar $-\mathrm{OH}$ groups lead to increased formation of Form I. $^{15}$ The observations both from LAG and POLAG were rationalized earlier based on the presence of a non-polar slip plane (200) in Form I (and absence of such in Form II) which interacts favorably with non-polar liquids. ${ }^{29}$

In our study of this system with IL-AG, we wanted to determine (i) if it is possible to employ hydrophobic and nonpolar ILs to stabilize the non-polar slip plane (200) leading to exclusive observation of Form I, and (ii) what happens when the alkyl chain lengths are systematically varied on an imidazolium cation? We thus, first investigated the series of ILs $\left[\mathrm{C}_{n} \operatorname{mim}\right]\left[\mathrm{NTf}_{2}\right](n=2,4,8,12)$. The experimental procedures used were the same as described above for our studies of CAF-CA.

We monitored the CAF-GLU system again using PXRD. Form I cocrystals (blue band) are identified with peaks at $c a$. $2 \theta=7^{\circ}$ and $10.5^{\circ}$, while Form II (red band, Fig. 3) can be monitored by peaks at $c a .2 \theta=8^{\circ}$ and $15^{\circ}$. The presence of peaks at ca. $2 \theta=12^{\circ}$ indicates the presence of unreacted CAF (grey band). Employing catalytic amount of all these hydrophobic ILs lead to Form I, however, increasing the alkyl chain length on the imidazolium cation leads to a decrease in the rate of cocrystal formation during mechanochemical grinding. Although, it is difficult to quantify the exact extent of cocrystallization in these studies, the amount of unreacted CAF increased with increasing alkyl chain length as can be seen in Fig. 2.

Next, three additional ILs with varying polarity $\left[\mathrm{OHC}_{2} \mathrm{mim}\right]\left[\mathrm{NTf}_{2}\right],\left[\mathrm{C}_{2} \mathrm{mim}\right]\left[\mathrm{BF}_{4}\right]$, and $\left[\mathrm{OHC}_{2} \mathrm{mim}\right]\left[\mathrm{BF}_{4}\right]$ were studied. As mentioned above, the grinding experiment with hydrophobic $\left[\mathrm{C}_{2} \mathrm{mim}\right]\left[\mathrm{NTf}_{2}\right]$ resulted in the exclusive formation of Form I with traces of CAF present in the mixture. Similar outcomes were also observed with the employment of $\left[\mathrm{OHC}_{2} \mathrm{mim}\right]\left[\mathrm{NTf}_{2}\right]$ and $\left[\mathrm{C}_{2} \mathrm{mim}\right]\left[\mathrm{BF}_{4}\right]$ as grinding liquid. However, while ground with $\left[\mathrm{OHC}_{2}\right.$ mim $]\left[\mathrm{NTf}_{2}\right]$, the absence of representative peaks of CAF probably indicated better conversion to the cocrystals. When the grinding IL was changed from $\left[\mathrm{OHC}_{2} \mathrm{mim}\right]\left[\mathrm{NTf}_{2}\right]$ to $\left[\mathrm{OHC}_{2} \mathrm{mim}\right]\left[\mathrm{BF}_{4}\right]$, the cocrystals formed were predominantly Form II with traces of Form I present. As the polymorphic preference changes from Form I to Form II with the change of anions and overall hydrophobic-hydro-

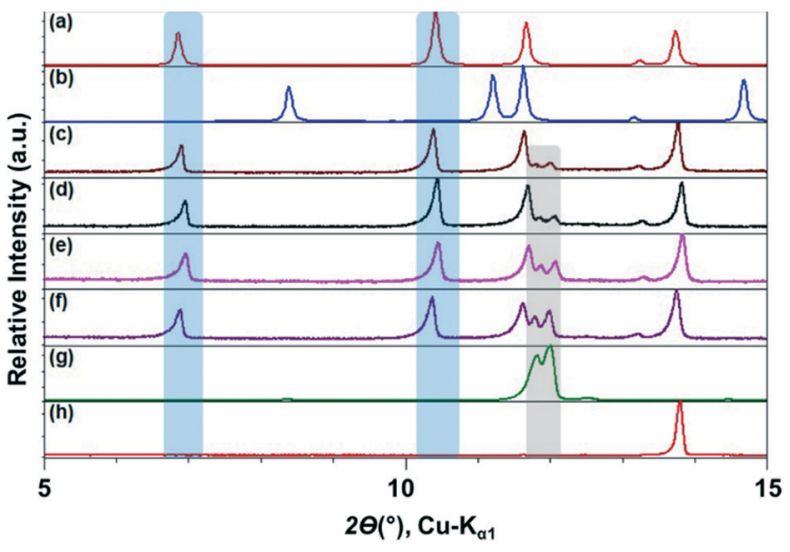

Fig. 2 Simulated pattern of CAF-GLU Form I (monoclinic) (a), simulated pattern of CAF-GLU Form II (triclinic) (b), the ground powder of CAF-GLU as obtained from $\left[\mathrm{C}_{2} \mathrm{mim}\right]\left[\mathrm{NTf}_{2}\right]$ (c), $\left[\mathrm{C}_{4} \mathrm{mim}\right]$ $\left[\mathrm{NTf}_{2}\right](\mathrm{d}),\left[\mathrm{C}_{8} \mathrm{mim}\right]\left[\mathrm{NTf}_{2}\right](\mathrm{e}),\left[\mathrm{C}_{12} \mathrm{mim}_{[} \mathrm{NTf}_{2}\right](\mathrm{f}), \mathrm{CAF}(\mathrm{g})$ and GLU (h) used in the grinding experiments.

philic nature of the IL, these results indicate towards the role of anions in the cocrystal formation (Fig. 3).

The observations in CAF-GLU system illustrate a vital point that the changes in crystallization outcome could often be accomplished by modifying only one ion, while keeping the other ion the same. As the hydrophobicity is controlled mainly by the anions in the given set of ILs, the modification of the cation with respect to differing alkyl chain lengths contributed in the different rate of formation of Form I CAFGLU cocrystals whereas a change in the nature of the anions (e.g., while going from $\left[\mathrm{OHC}_{2} \mathrm{mim}\right]\left[\mathrm{NTf}_{2}\right]$ to $\left[\mathrm{OHC}_{2} \mathrm{mim}\right]\left[\mathrm{BF}_{4}\right]$ ) lead to the change in the overall polymorphic outcome. This type of subtle adjustment of the overall environment of the ILs by modifying only one component offers fine tuning of the crystallization outcome.

To investigate the generality of these observations further, we tried to investigate the previously published crystal structure of $\mathbf{C A F}-\mathbf{C A}^{21}$ in detail using the coordinates taken from

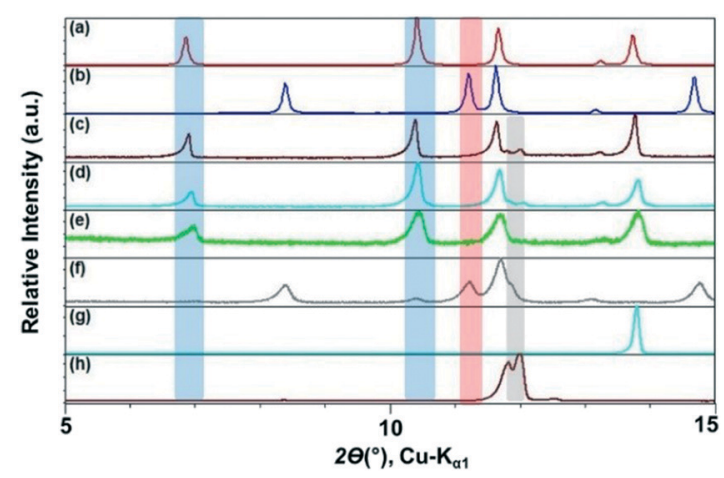

Fig. 3 Simulated pattern of CAF-GLU Form I (monoclinic) (a), simulated pattern of CAF-GLU Form II (triclinic) (b), the ground powder of CAF-GLU as obtained from $\left[\mathrm{C}_{2} \mathrm{mim}\right]\left[\mathrm{NTf}_{2}\right]$ (c), $\left[\mathrm{C}_{2} \mathrm{mim}_{[}\left[\mathrm{BF}_{4}\right]\right.$ (d), $\left[\mathrm{OH} \mathrm{C} \mathrm{C}_{2} \mathrm{mim}\right]\left[\mathrm{NTf}_{2}\right]$ (e), $\left[\mathrm{OH} \mathrm{C} \mathrm{mim}_{2} \mathrm{BF}_{4}\right]$ (f), experimental powder pattern of GLU $(\mathrm{g})$ and $\mathrm{CAF}(\mathrm{h})$ used in the grinding experiments. 
the CSD. ${ }^{30}$ Form I of CAF-CA shares a striking similarity in primary and secondary synthon patterns (Fig. 4) with CAF-GLU Form I and a non-polar slip plane along (200) is present in the structure of CAF-CA as shown in Fig. 4. Therefore, successful isolation of Form I CAF-CA cocrystal with the employment of the relatively hydrophobic ILs may share the same origin as the formation of Form I of CAFGLU. Although ILs differ from either organic solvents or the EG based polymer derivatives in terms of interactions, the similarity of the observations in both the cases indicate the importance of relatively non-polar and hydrophobic ILs in stabilizing the (200) slip plane and may be indicative of the importance of IL micro-environments to affect the nucleation and growth stages, hence in determining the polymorphic outcome.

In summary, we have employed ILs in a mechanochemical grinding approach to see how the nature of ILs affect the crystallization outcome. For the first system, CAF-CA, the importance of IL as grinding liquid was illustrated whereas for the second system, CAF-GLU, the polymorphic outcome of the cocrystal systems were investigated systematically with respect to IL structural variables such as the alkyl chain lengths on imidazolium cations and by changing the anions and hydrogen bonding ability of the IL components. At the end, polymorphic preferences of CAF-GLU and CAF-CA systems may be controlled by the interactions of the respective ILs with the slip planes present in these systems.

Ionic liquid-assisted grinding represents a promising approach in mechanochemistry. As many properties of ILs can be tuned systematically, either by individual tuning of the individual ionic components or in a dual manner, this approach provides a better platform with wider tuning range as compared to either the organic solvents or the polymers. In this work, we have shown that changing either of the components in a systematic way contribute to different aspects of mechanochemical synthesis. A slight modification of the alkyl part on the imidazolium cation mainly contributes towards subtle control of rate of cocrystal formation while change in the overall hydrophobicity-hydrophilicity by chang-
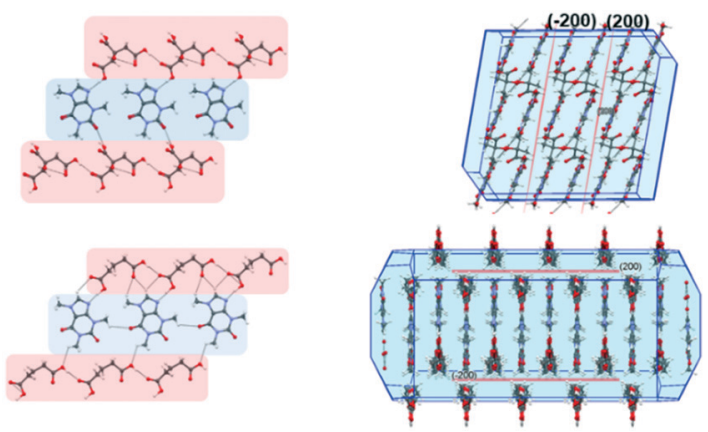

Fig. 4 Synthon patterns and packing diagram of CAF-CA and CAFGLU (Form I) (top to bottom). Note the similarity between primary and secondary synthon structures in all three structures. Also note that the slip planes exist along (200) in CAF-CA and CAF-GLU (Form I). ing the anions of the hydroxylated ILs contributed to a drastic change in the overall polymorphic outcome. This aspect of IL-AG may allow rational cocrystal design in future, as well as provide access to some otherwise inaccessible cocrystal polymorphs. This approach adds to the diversity in liquid assisted grinding techniques and provides more variables in terms of systematic tuning of the properties of grinding liquid. Hence, it carries importance to various fields including crystal engineering, ILs, and mechanochemistry.

We thank Novartis for their financial support.

\section{Conflicts of interest}

There are no conflicts to declare.

\section{Notes and references}

1 S. Aitipamula, et al., Cryst. Growth Des., 2012, 12, 2147-2152.

2 A. Myerson, Handbook of industrial crystallization, Butterworth-Heinemann, 2002.

3 G. R. Desiraju, Angew. Chem., Int. Ed., 2007, 46, 8342-8356.

4 A. Mukherjee and G. R. Desiraju, Chem. Commun., 2011, 47, 4090-4092.

5 L. R. MacGillivray, J. L. Reid and J. A. Ripmeester, J. Am. Chem. Soc., 2000, 122, 7817-7818.

6 L. R. MacGillivray, G. S. Papaefstathiou, T. Friščić, T. D. Hamilton, D.-K. Bučar, Q. Chu, D. B. Varshney and I. G. Georgiev, Acc. Chem. Res., 2008, 41, 280-291.

7 N. A. Mir, R. Dubey and G. R. Desiraju, IUCrJ, 2016, 3, 96-101.

8 N. Shan and M. J. Zaworotko, Drug Discovery Today, 2008, 13, 440-446.

9 N. J. Babu and A. Nangia, Cryst. Growth Des., 2011, 11, 2662-2679.

10 D. Braga and F. Grepioni, Angew. Chem., Int. Ed., 2004, 43, 4002-4011.

11 S. L. James, et al., Chem. Soc. Rev., 2012, 41, 413-447.

12 N. Shan, F. Toda and W. Jones, Chem. Commun., 2002, 2372-2373.

13 N. Madusanka, M. D. Eddleston, M. Arhangelskis and W. Jones, Acta Crystallogr., Sect. B, 2014, 70, 72-80.

14 D. Hasa, G. Schneider Rauber, D. Voinovich and W. Jones, Angew. Chem., Int. Ed., 2015, 54, 7371-7375.

15 D. Hasa, E. Carlino and W. Jones, Cryst. Growth Des., 2016, 16, 1772-1779.

16 C. P. Price, A. L. Grzesiak and A. J. Matzger, J. Am. Chem. Soc., 2005, 127, 5512-5517.

17 W. M. Reichert, J. D. Holbrey, K. B. Vigour, T. D. Morgan, G. A. Broker and R. D. Rogers, Chem. Commun., 2006, 4767-4779.

18 C. C. Weber, S. A. Kulkarni, A. J. Kunov-Kruse, R. D. Rogers and A. S. Myerson, Cryst. Growth Des., 2015, 15, 4946-4951.

19 Q. Zeng, A. Mukherjee, P. Muller, R. D. Rogers and A. S. Myerson, Chem. Sci., 2018, 9, 1510-1520.

20 T. Friščić, D. G. Reid, I. Halasz, R. S. Stein, R. E. Dinnebier and M. J. Duer, Angew. Chem., Int. Ed., 2010, 49, 712-715. 
21 S. Karki, T. Friščić, W. Jones and W. D. S. Motherwell, Mol. Pharm., 2007, 4, 347-354.

22 J. P. Smit and E. J. Hagen, J. Chem. Crystallogr., 2015, 45, 128-133.

23 B. Gharib and A. Hirsch, Eur. J. Org. Chem., 2014, 2014, 4123-4136.

24 H. Wang, G. Gurau, S. P. Kelley, A. S. Myerson and R. D. Rogers, RSC Adv., 2013, 3, 10019-10026.

25 K. E. Gutowski, G. A. Broker, H. D. Willauer, J. G. Huddleston, R. P. Swatloski, J. D. Holbrey and R. D. Rogers, J. Am. Chem. Soc., 2003, 125, 6632-6633.
26 S. Zhang, X. Qi, X. Ma, L. Lu and Y. Deng, J. Phys. Chem. B, 2010, 114, 3912-3920.

27 R. Thakuria, M. D. Eddleston, E. H. H. Chow, G. O. Lloyd, B. J. Aldous, J. F. Krzyzaniak, A. D. Bond and W. Jones, Angew. Chem., Int. Ed., 2013, 52, 10541-10544.

28 Z. Q. Yu, P. S. Chow, R. B. H. Tan and W. H. Ang, Cryst. Growth Des., 2011, 11, 4525-4532.

29 A. V. Trask, W. D. S. Motherwell and W. Jones, Chem. Commun., 2004, 890-891.

30 C. R. Groom, I. J. Bruno, M. P. Lightfoot and S. C. Ward, Acta Crystallogr., Sect. B, 2016, 72, 171-179. 